\title{
Ensuring Academic Integrity in Online Assessments: A Literature Review and Recommendations
}

\author{
Fariza Sabrina, Salahuddin Azad, Shaleeza Sohail, and Sweta Thakur
}

\begin{abstract}
During the recent COVID-19 outbreak, educational institutions have transitioned to online teaching for all students for most of the programs. Due to lack of in-person interactions and monitoring, assessments in online courses may be more susceptible to contract cheating, collusion, fabrication and other types of academic misconduct than the assessments in face-to-face courses. This situation has raised several research questions that need immediate attention, such as what are the best possible options for online assessments and how to administer online assessments so that academic integrity could be preserved. The authors have conducted a scoping study and carried out an extensive literature review on i) different types of assessments that are suitable for online courses, ii) strategies for ensuring academic integrity, and iii) methods, tools and technologies available for preventing academic misconduct in online assessments. It is evident from the literature review that there are a range of options available for designing assessment tasks to detect and prevent violations of academic integrity. However, no single method or design is enough to eliminate all sorts of academic integrity violations. After thorough research and analysis of existing literature, the authors have provided a comprehensive set of recommendations that could be adopted for ensuring academic integrity in online assessments.
\end{abstract}

Index Terms-Academic integrity, COVID-19, online assessments, online courses.

\section{INTRODUCTION}

Academic integrity has always been a very important topic in education. It is even more critical for online education [1]-[3]. As students cannot be physically monitored in online mode, they can easily engage in academic misconduct without being detected by the academic staff. Existing research shows that students' grades are higher in online exams compared to face-to-face exams and cheating in online exams might be a possible reason for this gap in grades [4]. Clark et al. [5] also suggested that online exams are vulnerable due to the presence of academic misconduct opportunities. Fask et al. [6] found that poor performing, and less engaged students are more likely to cheat in unproctored exams. Moreover, recent advancements in technologies have led to the invention of new ways of cheating.

Manuscript received June 15, 2021; revised July 26, 2021

Fariza Sabrina and Salahuddin Azad are with School of Engineering and Technology, Central Queensland University, Australia (e-mail: f.sabrina@cqu.edu.au, s.azad@cqu.edu.au).

Shaleeza Sohail is with School of Information and Physical Sciences, The University of Newcastle, Australia (e-mail: shaleeza.sohail@newcastle.edu.au).

Sweta Thakur is with School of Information Technology, King's Own Institute, Australia (e-mail: sweta.thakur@koi.edu.au).
Due to the outbreak of COVID-19, many countries have imposed much-needed restrictions which forced higher education institutions to transition from on-campus teaching to online delivery for all students. Moreover, most universities have reconsidered their assessment strategies because of this quick and abrupt transition [7], [8]. While education providers have provisionally converted to fully online mode education, it is of paramount importance to ensure academic integrity in teaching and learning.

Even before the COVID-19 situation, there have been growing interests in online/distance learning in higher education because of the convenience and flexibility of maintaining work/life balance. The COVID-19 pandemic might further increase the popularity of online education among students, teachers and educational institutions. With the increase in the popularity of online education, there has been an increase in frequency as well as the number of ways of committing academic misconduct in online assessments. So even after the COVID-19 crisis is over, more higher education institutions would consider increasing adoption of online teaching and hence, would need to look at ways to preserve academic integrity.

The aim of this paper is to make a comprehensive set of recommendations for designing and administering assessments in online environments to ensure academic integrity. For this purpose, the authors have conducted an extensive literature review to identify the range of research relevant to i) different types of assessments that are suitable for online courses, ii) strategies for ensuring academic integrity, and iii) methods, tools and technologies available for preventing academic misconduct in online assessments. The literature review found a substantial amount of research conducted in these areas related to techniques and methods that only focus on a particular academic integrity issue. However, no single measure can provide a foolproof remedy for all kinds of academic misconduct. Therefore, it is essential to come up with a comprehensive set of multi-faceted recommendations with support from state-of-the-art tools and technologies so that academic integrity is ensured in all online courses.

The rest of the paper is organised as follows: Section II discusses our research questions and methodology. Section III provides an extensive literature review of different assessment options for online courses, academic integrity issues in those assessments, and strategies, methods, tools and techniques to preserve academic integrity. Section IV provides a comprehensive set of multi-faceted recommendations based on the current literature and the authors' own analysis. Finally, Section V concludes the paper. 


\section{ReSEARCH Methodology}

The authors have conducted a "scoping study" [9], the purpose of which is to summarise the research findings in the existing literature and identify research gaps in the area of maintaining academic integrity in online assessments. The authors have followed the guidelines provided in [9] to conduct this study and drawn a conclusion from the existing literature about the state of research in this field.

\section{A. Research Questions}

With online education becoming very common and essential in recent times, academic integrity has become a crucial issue. It is essential to have an account of current policies, measures, techniques and methods to find major aspects and research gaps in this domain. As such, the guiding research questions for this review are:

- What are the different assessment options for online courses?

- What strategies have been proposed to ensure academic integrity in online courses?

- What methods, tools and technologies have been in use to prevent academic misconduct in online assessments?

\section{B. Data Sources and Search Strategy}

For the literature review, the authors first searched IEEE Xplore Digital Library and Education Research Complete (Ebscohost). Both the databases returned a limited number of publications. Hence, Google Scholar has been considered as that provides a high number of quality research publications in the relevant areas. Even though Google Scholar provided more than 2000 papers in the initial search, the first screening revealed that most of the papers were not relevant. Hence, Google search was used to find more relevant papers.

For the search in each database, the authors tested a combination of keywords, which are "academic misconduct", "online" and "techniques" as well as their synonyms.

Due to the low number of articles for some particular topics, some publications before 2015 were also considered.

\section{Selection Criteria}

The authors have chosen articles for the literature review based on the selection and eligibility criteria mentioned below. Only the peer reviewed full-text conference papers and journal articles published in English were considered.

\section{Inclusion:}

All articles that are directly related to at least two of the three research questions have been selected to find more focused areas.

\section{Exclusion:}

The articles reporting academic integrity issues in general or more focused towards face-to-face teaching as well as the articles related to the following themes were excluded: no academic integrity issues explicitly identified, related to marking, peer assessment/self-assessment, language other than English, accreditation/CPA related, self-testing, learning styles, oral exams, no full text, statistical analysis, online tools, experiences, exam notes, student performance, activities or scores, AI/machine learning, examinees acceptance, alternative assessment strategies.

Study Selection:
Identification: The search in November 2020 identified a total of 2639 articles, from Google Scholar ( $n=2490)$, IEEE Xplore $(n=5)$ and Ebscohost $(n=144)$. The duplicated $(n=3)$ articles were excluded from the research. The first 50 pages of Google search resulted in collecting articles $(n=117$, not considering duplicated articles) that seemed relevant to this research.

Screening:

The preliminary screening was conducted by reading the titles and abstracts of the results by all four authors to remove any unrelated work. This screening resulted in removing 2268 articles and 485 articles remained.

Eligibility:

The first iteration of article assessment required reading of the full-text articles to eliminate any unrelated articles. This iteration resulted in removing 233 articles and 252 remaining articles.

In the second iteration, all authors thoroughly looked for articles that illustrate strategies, methods, tools and technologies for ensuring academic integrity for online education and/or contribute to the research questions. The second iteration resulted in elimination of 210 articles and 42 articles remained. Fig. 1 shows the complete article screening process, and the resulting articles reviewed.

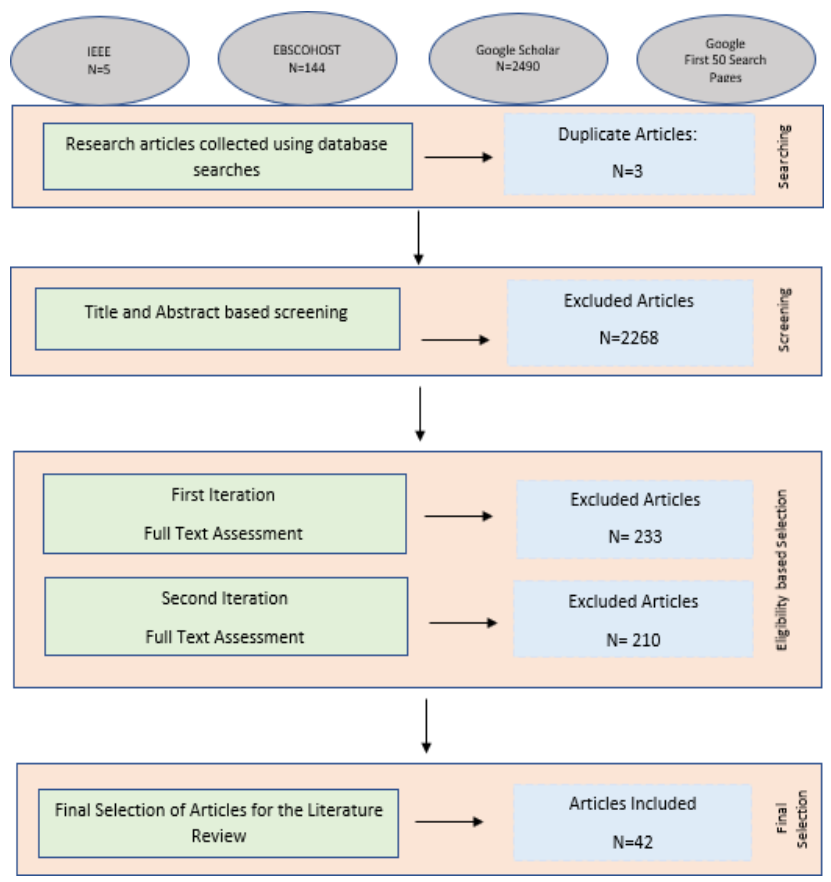

Fig. 1. Scoping review overview.

\section{LITERATURE REVIEW}

This section thoroughly reviews the articles relevant to the research questions, collected following the methodology mentioned in the previous section.

\section{A. Different Assessment Options}

The effective design of any course requires appropriate selection of assessment types to evaluate student learning. Mapping assessments to the subject learning outcomes and graduate learning outcomes is a complex task.

Sewell et al. [10] analysed assessment design strategies for online courses and emphasised the importance of aligning 
subject learning outcomes to the design of formative and summative assessments. The authors suggested the use of formative assessments to check students learning and for providing feedback to improve learning experience. On the other hand, summative assessments are the means to evaluate a student's learning achievement and therefore, ensuring academic integrity of these types of assessments is crucial.

There are various types of assessments used in different study programs offered online. The most common assessments suitable for online courses are [3]:

- paper/essay,

- written assignment,

- exam/quiz,

- online discussion,

- project/simulation/case study,

- reflection,

- presentation,

- field work,

- portfolio,

- peer evaluation.

From an academic integrity point of view, most of the assessments other than exams/tests face the same challenges irrespective of the mode of delivery. Hence, the academic integrity challenges faced by both non-exam and exam assessments were addressed separately in the following subsections.

\section{1) Non-exam assessments}

With the increasing use of learning management systems (LMS) in higher education institutions, assessments are generally submitted online, a common practice is to use similarity checking tools to identify possible collusion and plagiarism. However, contract cheating cannot be detected using simple similarity checking tools. Contract cheating in assessments, where students engage an external party in completing an assessment, is a big concern in both online and face-to-face settings [11]. There has been a rise in contract cheating in recent years in higher education institutions in Australia and overseas. The education sector along with the government in Australia is trying to minimise the prevalence of contract cheating for ensuring the quality of education.

Ellis et al. [12] found that the authenticity factor is not very effective in reducing outsourcing of assessments despite existing literature suggesting that authentic assessment design plays an important role in reducing contract cheating. According to the authors, while it is still important to design authentic assessments, other factors such as educating students about ethical behaviour, making them aware of university policies and procedures, having more emphasis on detection of academic misconduct cases and taking an appropriate action once a misconduct case is detected could be more helpful in preventing academic misconduct.

Viva or oral examination can be used to check students' understanding of the assessment tasks and verify their submissions. Sotiriadou et al. [13] found that oral examination could be used as a form of authentic assessment, and it could also be successfully used in preventing academic misconduct in both online and face-to-face settings.

\section{2) Online exams and tests}

Exams are one of the most traditional ways of assessing students and are prevalent in face-to-face learning. Exams are especially useful in judging a student's aptitude to recall knowledge, and analytical ability. Closed book exams need to be administered under strict rules and generally require invigilators/proctors to maintain integrity. Even when these exams are conducted online, the requirement of invigilation and proctoring cannot be overlooked. In online courses, the following options are available for conducting exams, tests, and quizzes:

- Human proctored test/exam [14]

- Technology based proctored test/exam [15]

- Non-proctored online test/exam

- Real-time online quiz-based test

Being resource intensive and less flexible, closed book exams may not be suitable for all courses. Open book and take-home exams allow students to use their text and other resources, therefore, students are less tempted to cheat. As these types of exams are conducted at higher levels of Bloom's taxonomy [16], proctoring for these exams is not essential.

Teclehaimanot et al. [17] identified several legal requirements for conducting online exams. One of the most important requirements is student identification and authentication while taking online exams. The United States Higher Education Opportunity Act (HEOA) of 2008 mandates educational institutes to verify the identity of students enrolled in distance mode courses in at least one of the following ways [18]:

- A secure login and password

- Proctored examinations

- Any other technologies and methods that can effectively verify students' identity

To the best of the knowledge of the authors of this paper, there is no such legislation in Australia that mandates the verification of the identity of participants in online courses. However, all educational institutions require students to login using an ID and password before taking online tests or submitting assignments.

The choice of assessments depends on the field of study, learning outcomes, and availability of resources. For certain assessments like hand-in assignments and take-home exams, extensive proctoring or monitoring may not be necessary but other measures such as similarity checking is essential. On the other hand, assessments like quizzes and closed book exams need to have human proctoring or technology-based authentication for ensuring academic integrity. The following section reviews the strategies to ensure academic integrity of assessments in online courses.

\section{B. Strategies and Methods to Ensure Academic Integrity}

When it comes to carrying out assessment tasks, academic integrity means the assessment tasks are completed by students on their own (individually or in a group) and the materials submitted are their original contributions, except for the materials that are referenced, without having unauthorised collaboration, external help, or undue advantage. Academic integrity is violated in many different ways, the most prominent ones are bribery, misrepresentation, plagiarism, cheating, collusion, duplicate submission, conspiracy, fabrication, academic misconduct, improper 
computer/calculator use, improper online and blended course use, and disruptive behaviour [19]. Social networks allow students to share assignments and solutions, discuss answers, and commit group cheating while taking exams [20].

Absence of clear guidelines regarding academic integrity and related institutional policies can play a significant role on students' behaviour. A survey-based study conducted by McHaney et al. [21] found that students' perceived norms about academic integrity and knowledge of institutional policy were the most significant factors to differentiate the students and hence, it is imperative to encourage academics to incorporate the discussion of these policies in their subject curriculum.

In addition, McGee [2] suggested that defining academic dishonesty and specifying the consequences of misconduct on the curriculum reduces academic cheating. Benson et al. [22] exemplified the importance of an online academic integrity module that educates students about institutional academic integrity policy.

The exploratory research undertaken by El-Nakla et al. [23] showed that institutional policies may be ineffective in preventing academic misconduct if there is not enough awareness among academic staff and proper support and tools are not available to them to detect cheating. Hence, academic integrity policies and awareness must be supplemented with different measures of detection, deterrence and correction.

The results of the research conducted by Mott [24] showed that there is a strong positive correlation between the time allowed for an online assessment and frequency of cheating. Also, randomisation of question order was found to be effective in reduction of cheating if the number of visits/attempts is set properly.

Bedford et al. [25] provided some recommendations that could be useful for preventing cheating in online exams. The authors suggested the use of 360-degree span camera to monitor students during the exam. Use of multiple versions of an online test was recommended to reduce cheating when a number of students are taking the online test together. In order to promote non-sharing of work among students, use of similarity checking tools for online submissions was suggested.

McGee [2] suggested alternative methods of assessments such as randomised quizzes or tests using social media tools, tests that require students to use their text and require supporting evidence, arguments or reasoning, and allowing multiple attempts (where the highest score is taken) to ensure academic integrity in online courses. The author also recommended the following tactics for online tests and quizzes to reduce occurrences of cheating:

- Using true/false, matching and multiple-choice questions, and randomised answer choices

- Setting questions based on prior course work

- Conducting more frequent and shorter quizzes

- In calculation-based tests, providing students with different number sets

- Changing one-third of items every semester

Smith et al. [26] also suggested strategies for setting up quizzes such as ensuring questions include content from lecture/class discussions and avoiding generic questions in order to reduce academic misconduct.
Stack [27] studied the effectiveness of exam time duration as an inhibitor for reducing academic misconduct in online exams. Their study showed that online exams completed in a large time window (12 hours, 24 hours etc.) as compared to limited time window exams (a set start time and a small duration of 1 hour) exhibited significant collaborative cheating and higher exam scores. Hence, setting exams to start at a fixed time with minimum allowed time duration would reduce cheating opportunity significantly.

Santos et al. [28] found that randomised exam reduces students' suspicious activities. The authors suggested to prepare a fully randomised exam with a test bank of 500 to 1000 questions, which might not always be possible for all institutions due to time and related cost constraints. Clark et al. [5] suggested that the most effective technique to ensure academic integrity in an online exam is the use of a large question banks that limits students' ability to ask for online help. Golden and Kohlback [29] proposed an approach of paraphrasing exam questions to minimise academic misconduct in online exams even with test banks, which resulted in a reduction of academic misconduct in online exams for undergraduate accounting courses.

Lee [30] recommended the following strategies to be used in assessment design for ensuring academic integrity.

- Providing detailed marking rubric/criteria so that the student has a full understanding of the assessment requirements

- Using different types of assessment methods to test students' ability to apply a specific concept

- Submitting report for preapproval

- Include design assessment as it is more difficult to cheat

- Open-book assessments that evaluate students' conceptual understanding

- Putting a time limit for answering each question in exams so that only students having a deep understanding are able to answer it within the time limit

Progressive and reflective assessments could be an effective way to ensure the integrity of students' work. In progressive assessments, the later assessment tasks are progressions of the previous assessment tasks, which can make copying others' work difficult [2]. Reflective assessments require students to reflect on tasks performed during a group work in class or during a project work [31]. This would make it hard to complete assessment tasks with the help of a third party who has little knowledge about what has happened.

Albert and Jonathon [32] constructed a typology related to common online test design choices to inform educators about the implications of different design choices. The dimensions/design choices considered in their typology are: i) anticipated cognitive demand against the reward of achievement, ii) expected effectiveness of offloading, iii) stakes per assessment, iv) number of assessment items in allotted time, v) perishability of assessment items (i.e., reuse of assessment items may allow students to share answers), and vi) proctoring.

Cramp et al. [33] recommended systematic design foreasy navigation and minimal cognitive load along with clear and early communication with students for successful implementation of online exams. The authors also 
recommended having an exam rehearsal before the actual exam to make students familiar with the exam format. Moreover, a real-time support system is required to deal with any issues that may arise during the exam.

It is evident from the above discussion that no single method or design is enough to eliminate all sorts of academic integrity violations. Good assessment design accompanied by raising awareness of students, making university policies to verify students' identity and deal with academic misconduct cases can ensure academic integrity in online education. There are a growing number of technology-based solutions which could verify the validity of students' identity, ensure the authenticity of their work, and provide alternatives to human proctored tests, which are discussed in the following section.

\section{Tools and Technologies to Preserve Academic Integrity}

This section summarises most commonly used methods, tools and techniques for preventing academic misconduct in exams and tests, and compare the existing options based on the suitability, cost, ease of use and administrative overhead.

\section{1) Online proctoring options for online exams/tests}

The requirements of having the exams invigilated, online proctoring has been adopted as an alternative to physical proctoring for online exams and tests. Haus et al. [34] suggested that it is not effective for a teacher to monitor a large cohort of students during the exam and hence, usage of a commercially available system is advisable. After comparing two commercially available proctoring systems such as Respondus and Proctorio in terms of pricing, setup overhead, exam recording facility and AI algorithms used, the author suggested that Proctorio was better for monitoring exam sessions. Most proctoring services require financial and time commitments. In addition, it involves technological requirements and complicated integration with LMS, which may not be appropriate for many students and institutions [35]. However, when average student performances were compared with and without proctoring, it was found that average performance with proctoring was significantly lower than that of without proctoring emphasising that proctored exams represent true performance of students [1].

Slusky [36] analysed several security measures crucial for minimising academic misconduct during online exams even while using online proctoring systems, such as periodic authentication of the exam taker, use of webcam for behaviour monitoring, multi-factor and biometric authentication. The author suggested use of three categories of control for online proctoring systems - administrative, physical and technical, with a variety of approaches available for each category. The author concluded that even though a huge number of options are available for securing online exams, these should be selected by the instructor based on their suitability as well as the students' perception of the class.

Adetoba et al. [37] proposed a data mining framework for monitoring the environment of online exams. After preprocessing, feature extraction, and transformation, a Bayesian classifier is used for classification due to the independence among the predictors. The authors concluded that use of such framework would provide adequate security for reducing academic misconduct in online exams.

Atoum et al. [35] proposed a multimedia-based system for automatic online exam proctoring. The system requires a webcam, a wearcam and a microphone to capture audio and video information which is used for detection of cheating. Users' features were extracted from information such as user verification, active window detection, gaze estimation, text detection, speech detection, and phone detection. The authors concluded that this system is affordable and efficient in detecting cheating during exams, but future research should focus on behaviour recognition.

Asep and Bandung [38] proposed a Convolutional Neural Network (CNN) based user verification system for online exams, which requires users' images to be captured in different poses and lighting conditions to establish user identity. Additionally, images are taken at random times during lecture sessions as part of the $\mathrm{CNN}$ based incremental training process. The trained model will be used for user verification once the user logs into the system for an online exam. The proposed system assumes that users will be taking online exams via mobile phones and thus, this system might not be suitable for all cases.

Khalaf et al. [39] presented the experience of implementing and running four components of a final exam online for final year dental students during the COVID -19 pandemic. In this exam setting, two mobile phones were used (one on the side and one behind the students) to check whether students were looking at any material behind their PC or laptop's camera that was used for blackboard recording. Although this study demonstrated a promising outcome, this setup is not feasible for all institutions.

Natawiguna and Liem [40] investigated and compared two types of virtualisation methods for securing online exams conducted remotely and found that hardware-level virtualisation is a better solution than operating system level virtualisation as it provides a better level of isolation by restricting exam takers within a sandbox.

Wong and Tang [41] designed and implemented online assessments in different formats and invigilation methods. Among various combinations of the settings, displaying questions one at a time, randomising the order of questions or answers and the use of Lockdown Browser with Response Monitor plus Zoom monitoring turned out to be the most effective configuration. However, the settings are only effective when a stable internet connection is maintained, and clear instructions and guidelines are provided to both examiners/invigilators and students.

\section{2) Authentication techniques for online exams / tests}

One major factor to ensure academic integrity in online exams is to verify a student's identity before the start of the exam. Biometric features can be used to verify a student's identity while taking online exams, such as fingerprint, signature, facial features, or voice recognition.

Mugambi et al. [42] proposed a student verification model to validate the identity of distance students to curb cheating in e-assessments. The model uses two features - keystroke dynamics and stylometric analysis to generate the features of a student's writing. Keystroke dynamics features consist of the mean and standard deviations of the key press durations, 
transition times and number of key press for space, backspace, delete, insert, home, enter, arrow keys, left and right shift key. Stylometric features consist of the average word/sentence length, frequency of function words, use of punctuation, frequency of keywords and n-grams. The unknown feature vectors are compared against the pre- recorded feature vectors to validate the authenticity of a student.

Lee-Post and Hapke [43] discussed various authentication solutions for providing access to registered users based on biometrics, surveillance, and predictive analytics in online assessments. The authors proposed the use of knowledgebased authentication solutions based on a user ID and password scheme that may also include challenge or security questions, Ullah et al. [44]. Biometric-based authentication solutions can also be used for this purpose.

Chuang et al. [45] identified two features of test taker's behaviour, which could reliably predict the cheating behaviour. The features are time delay, and the variation of test taker's head pose relative to the computer screen. The authors developed a logit model to predict cheating, which demonstrated an accuracy of $75.6 \%$.

Aisyah et al. [46] developed a prototype of an authentication system to authenticate online exam participants in a remote setting. This system comprises of two Android-based modules - authentication and supervision modules. In this application, pictures were taken during the exam in random time intervals and the images were saved in a database in real time. Pictures were also taken prior to the test as a reference. The supervision module was developed for admins to validate examinees using the images taken prior to and during the test.

Young et al. [47] investigated the efficacy of using keystroke dynamics to authenticate students in online courses. The study examined different ways of constructing keyprint signatures. A keyprint signature is a person's typical typing behaviour. The study found that keyprint signature cannot reliability reveal the identity of a person typing a sample; however, it can reliably detect if the person typing the sample is not the one sought after.

The study by Trezise et al. [48] revealed that the keystrokes and clickstream data can be leveraged to successfully detect if a piece of text, typed on online word-processing software, is a student's own work or copied from another source. The analyses in this work revealed that participants typed in shorter bursts with longer pauses and more revisions when asked to complete a free-writing task compared to a transcription task. The cognitive processes (planning, translating and revision) behind free writing tasks make the typing pattern for free writing tasks uniquely different form that of transcription tasks.

Edwards et al. [49] illustrated a new plagiarism detection tool named TeSLA, which can assess the severity of plagiarism in the student submissions. TeSLA incorporated e-authentication tools such as voice and facial recognition, keystroke dynamics, forensic analysis and anti-plagiarism tool to be called seamlessly to authenticate students. TeSLA is able to provide immediate feedback, but it can only do so after the final piece of work is submitted. The tool is not able to provide any assistance during the time of producing the work.
The various methods of authentication suggested in the literature have both pros and cons. The most commonly used options such as user ID/password, security questions etc. are not completely reliable as students may share these credentials in order to allow someone else to take the exam on their behalf. The deciding factor for selection of these options is the purchase or subscriptions cost of special software and hardware as well as technical and administrative support needed.

\section{3) Authentication techniques for online exams / tests}

There are software tools available and being used frequently by higher education institutes to detect plagiarism in assignments by checking the text of submitted works. Such tools can be incorporated into online exams and tests to detect plagiarism to some extent. Some of the popular plagiarism detection software that check for similarity in the text are as follows:

- Turnitin [50]

- Viper [51]

- Safe assign [52]

- Plagscan [53]

These tools can quickly scan through a large database to find similarity in the text in order to detect plagiarism. However, these are not foolproof as it is possible to create software which can make word-by-word substitution to deceive the similarity checkers. In future, similarity checkers would need to have the capability to look at the semantics, not just words to detect plagiarism.

Teclehaimanot et al. [17] investigated three remote nonproctored testing tools to determine an effective approach for online examination. The tools investigated in this study are:

1) a non-proctored recorded online testing environment (Respondus Monitor),

2) a non-proctored lockdown online testing environment (Respondus LockDown Browser), and

3) a non-proctored online testing environment (Blackboard Test and Survey Tool).

This study found that technology- based non-proctored testing tools (such as Monitor) could be effectively used if human proctored testing is not possible. This study was based on a small data set and suggested that further studies were required with a larger dataset. The suitability of these options is limited to the institutions that can afford such options and provide technical support to their students.

Ensuring academic integrity in online assessments is a complex issue due to having various dimensions involved, so no single measure can provide foolproof remedy for all kinds of academic misconduct. Therefore, a comprehensive set of multi-faceted strategies, methods, techniques and tools need to be readily adopted by the educational institutions to ensure academic integrity in online assessments.

\section{RECOMMENDATIONS TO ENSURE ACADEMIC INTEGRITY}

This section provides a comprehensive set of recommendations based on the current literature, which can be adopted for ensuring academic integrity in online assessments. However, not all recommendations are suitable for every online course. Hence, careful consideration is 
needed while designing assessments to suit the needs of the course and institution.

The recommendations are categorised into three main aspects (as shown in Fig. 2). The recommendation categories are built upon each other for support and impact enhancement as shown in Fig. 3.

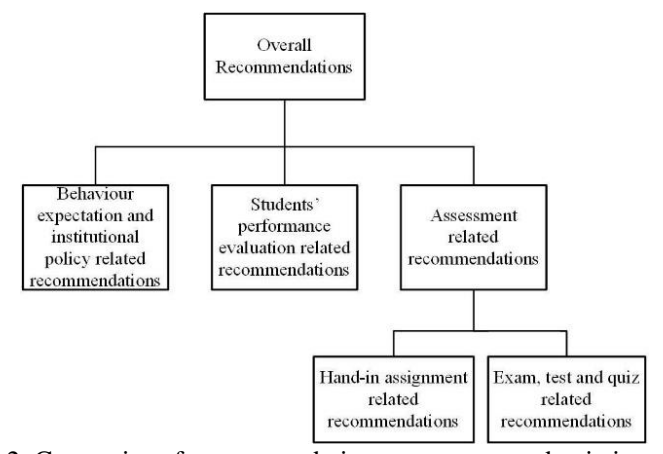

Fig. 2. Categories of recommendations to ensure academic integrity.

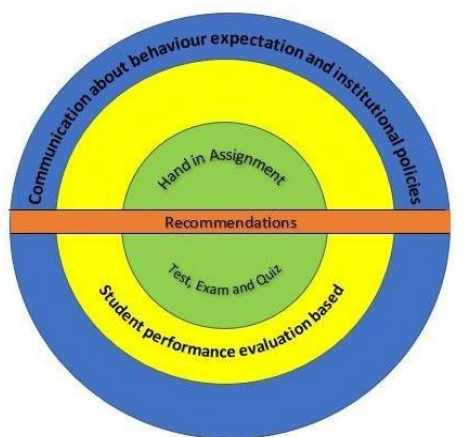

Fig. 3. Synergy between three categories of recommendations.

The first set of recommendations is for minimizing or preferably eliminating academic integrity issues by establishing an effective communication channel with students. The students should be clearly, concisely and timely informed of institutional policies related to academic integrity and behavioural expectations. Instead of directing students to the institutional policy webpage, subject coordinators and teaching staff need to make sure that students clearly understand what constitutes a violation of academic integrity.

As the interaction between academic staff and students is limited in online teaching, it is difficult to evaluate a student's true performance, which allows students to mimic good performance without achieving learning outcomes. The purpose of the second set of recommendations outline measures is to flag inconsistencies across multiple assessment results in a subject.

Careful design of assessment tasks plays a vital role in reducing academic misconduct. The third set of recommendations outline strategies for designing and administering different types of assessments such as hand-in assignments, exams, tests and quizzes as discussed below:

- Hand-in assignments are always prone to academic misconduct even in face-to-face courses due to their very nature. The recommended measures would encourage students to complete the assessment tasks by themselves or make it difficult to complete tasks without learning the subject content and to copy assignments without being detected.

- The nature of exam and tests dictates the measures required to minimize academic misconduct. Open book exams may not need such strict policies as closed book exams. Online quizzes are generally LMS based and may have different types of questions like multiple choice questions, true/false and higher-level analytical questions. The recommended measures would make sure the right person is taking the test, reduce students' opportunity to collect answers from another source, or make it difficult to answer questions without having a deep understanding of the subject content.

Our recommendations and rationale for those have been presented in detail in Table I.

TABLE I: OUR RECOMMENDATION, RATIONALE AND ACTION REQUIREMENT

\begin{tabular}{|c|c|c|c|}
\hline ASPECTS & RECOMMENDATIONS & RATIONALE & ACTION REQUIREMENTS \\
\hline $\begin{array}{l}\text { Communication about } \\
\text { behaviour expectation and } \\
\text { institutional policies }\end{array}$ & $\begin{array}{l}\text { During orientation an information session on } \\
\text { academic integrity and code of conduct should be } \\
\text { conducted for all new students. } \\
\text { An interactive and engaging compulsory academic } \\
\text { integrity module that clarifies institutional policies } \\
\text { with special emphasis on penalties related to any } \\
\text { academic misconduct should be introduced for all } \\
\text { commencing students. } \\
\text { In the very first meeting, teaching staff need to } \\
\text { provide clear guidelines about the expected } \\
\text { behaviour, especially academic integrity in their } \\
\text { subjects. } \\
\text { Assessment specifications must have clear } \\
\text { instructions related to academic integrity. While } \\
\text { discussing assessment specifications, academic staff } \\
\text { should discuss different types of academic integrity } \\
\text { issues and consequences of any academic } \\
\text { misconduct in a friendly but firm manner. } \\
\text { Any measures employed to ensure academic } \\
\text { integrity for a particular assessment should be } \\
\text { discussed with the students, for example, use of }\end{array}$ & $\begin{array}{l}\text { The literature suggests } \\
\text { that one of the most } \\
\text { important ways to ensure } \\
\text { academic integrity is } \\
\text { raising awareness among } \\
\text { students and make them } \\
\text { fully conscious of the } \\
\text { institutional policy and } \\
\text { procedures regarding } \\
\text { academic integrity. The } \\
\text { authors believe that the } \\
\text { suggested } \\
\text { recommendations will be } \\
\text { very effective in reducing } \\
\text { academic misconduct } \\
\text { cases if successfully } \\
\text { implemented. }\end{array}$ & $\begin{array}{l}\text { Proactive cooperation among } \\
\text { management, academic and } \\
\text { professional staff is required for } \\
\text { successful implementation of the } \\
\text { suggested recommendations. Staff are } \\
\text { required to be well aware of the } \\
\text { institutional policy and procedures. } \\
\text { Regular meetings/ training for staff on } \\
\text { policy and procedures would be very } \\
\text { helpful. }\end{array}$ \\
\hline
\end{tabular}




\begin{tabular}{|c|c|c|c|}
\hline & $\begin{array}{l}\text { Turnitin for assignments and proctoring services for } \\
\text { tests etc. }\end{array}$ & & \\
\hline $\begin{array}{l}\text { Student performance } \\
\text { evaluation related } \\
\text { recommendations }\end{array}$ & $\begin{array}{l}\text { While determining the final grade, instead of } \\
\text { calculating the percentage from the total mark of } \\
\text { all assessments, taking the average percentage of } \\
\text { all assessments. } \\
\text { Making use of various types of assessment tasks as } \\
\text { it would be unlikely for students to cheat in all types } \\
\text { of assessments [30]. } \\
\text { Conducting an investigation if a student's } \\
\text { performance varies widely across different } \\
\text { assessment items. } \\
\text { Having a minimum passing mark for some/all } \\
\text { individual assessment items so that a student is } \\
\text { required to perform consistently to demonstrate } \\
\text { his/her learning of the subject } \\
\text { content. }\end{array}$ & $\begin{array}{l}\text { Having a minimum } \\
\text { passing mark for all } \\
\text { assessments would make } \\
\text { sure students attempt all } \\
\text { assessments and perform } \\
\text { consistently, which would } \\
\text { be hard to demonstrate } \\
\text { without learning the } \\
\text { subject content. Moreover, } \\
\text { having various types of } \\
\text { assessment tasks would } \\
\text { make cheating very } \\
\text { difficult. The } \\
\text { recommendations would } \\
\text { not only reduce academic } \\
\text { misconduct cases but also } \\
\text { ensure students achieve the } \\
\text { learning outcomes. }\end{array}$ & $\begin{array}{l}\text { Academic staff, in consultation with } \\
\text { management, need to take decisions on } \\
\text { this matter after thorough analysis. }\end{array}$ \\
\hline $\begin{array}{l}\text { Hand-in assignment } \\
\text { related } \\
\text { recommendations }\end{array}$ & $\begin{array}{l}\text { - Assignment tasks need to be changed every } \\
\text { semester [2]. } \\
\text { Assignment tasks should be authentic and } \\
\text { engaging so students genuinely feel interested in the } \\
\text { assignment task. } \\
\text { Progressive assessment tasks should be developed } \\
\text { that require feedback from the teaching staff and } \\
\text { students should use that feedback to move to the } \\
\text { next task [2]. Such assessments would reduce the } \\
\text { possibilities of contract cheating and improve } \\
\text { student engagement. } \\
\text { If possible, an oral exam/viva component based } \\
\text { on the assessment task could be included as part of } \\
\text { the assessment task to reduce the temptation of } \\
\text { academic misconduct. } \\
\text { Participation in assessment related blogs, } \\
\text { discussion forums and online sessions could be } \\
\text { integrated into the marking scheme in order to make } \\
\text { sure students are engaged and have a medium to get } \\
\text { help. } \\
\text { Use of similarity checking software tools should } \\
\text { be enforced for all hand-in assignments. }\end{array}$ & $\begin{array}{l}\text { The recommended } \\
\text { measures would encourage } \\
\text { students to complete the } \\
\text { assessment tasks by } \\
\text { themselves or make it } \\
\text { difficult to complete tasks } \\
\text { without learning the } \\
\text { subject content and to copy } \\
\text { assignments without being } \\
\text { detected. }\end{array}$ & $\begin{array}{l}\text { Academic staff should carefully design } \\
\text { assignments so that they don't leave } \\
\text { any loophole that could be exploited by } \\
\text { students for cheating. It would be } \\
\text { beneficial if the institution could } \\
\text { arrange training on assessment design } \\
\text { forall new staff. }\end{array}$ \\
\hline $\begin{array}{l}\text { Exam, test and quiz } \\
\text { related } \\
\text { recommendations }\end{array}$ & $\begin{array}{l}\text { Using proctoring services to conduct closed book } \\
\text { exams and tests whenever possible. } \\
\text { If resources are available, using different } \\
\text { biometric and/or multimedia-based authentication } \\
\text { techniques for online exam/tests. } \\
\text { While conducting open book and take-home } \\
\text { exams, using high level analytical open-ended } \\
\text { questions that cannot be copied straightaway from } \\
\text { another source. } \\
\text { While taking online quizzes, allocating limited } \\
\text { time to answer each question and not allowing the } \\
\text { student to come back to a question once it is } \\
\text { answered. This will reduce the student's opportunity } \\
\text { to collect an answer from the text, Internet, or } \\
\text { another person. } \\
\text { Presenting each quiz question in two different } \\
\text { ways to confirm the student really knows the } \\
\text { answer. It is unlikely that the student will be able to } \\
\text { produce the correct answer twice without having the } \\
\text { knowledge about the topic. } \\
\text { Having surprise formative tests which are low } \\
\text { stake. The schedule for the tests will be known but } \\
\text { the topics for those tests will be unknown to the } \\
\text { students. Students wouldn't be able to prepare for } \\
\text { cheating and reveal their true knowledge level. This } \\
\text { will enable the teacher to gauge how much a student } \\
\text { knows. Any unpredictably good performance in the } \\
\text { summative exam will indicate possible cheating. } \\
\text { Asking random personal questions during online } \\
\text { exams/tests, which would be difficult for an }\end{array}$ & $\begin{array}{l}\text { For few subjects, it is } \\
\text { unavoidable to exclude } \\
\text { exams/tests even in online } \\
\text { mode. Some institutions } \\
\text { might also prefer to have } \\
\text { exams/tests for all/most } \\
\text { subjects delivered online. } \\
\text { The recommended } \\
\text { measures would make sure } \\
\text { the right person is taking } \\
\text { the test, reduce students' } \\
\text { opportunity to collect } \\
\text { answers from another } \\
\text { source, or make it difficult } \\
\text { to answer questions } \\
\text { without having a deep } \\
\text { understanding of the } \\
\text { subject content. }\end{array}$ & $\begin{array}{l}\text { Academic staff should cautiously } \\
\text { prepare exam, test and quiz questions. } \\
\text { A thorough understanding of Blooms } \\
\text { taxonomy and how to design questions } \\
\text { at each level is essential for all } \\
\text { academic staff. For using a proctoring } \\
\text { service, approval from higher } \\
\text { management would be required as it is } \\
\text { generally resource intensive. }\end{array}$ \\
\hline
\end{tabular}




\begin{tabular}{|l|}
\hline imposter to answer such as the student's score in the \\
last assignment, the coordinator of a subject the \\
student took last term, the number of subjects the \\
student has completed so far etc. \\
Conducting a follow-up online viva after the \\
exam. The viva questions will be based on the \\
answers provided by the student. \\
Changing exam/test questions every semester \\
Conducting exams/quizzes in a fixed time slot for \\
all students to minimise the sharing of answers. \\
Otherwise, different sets of questions should be \\
provided for each session.
\end{tabular}

\section{CONCLUSION}

In recent years, online education has gained tremendous popularity among students because of the convenience in learning experience and flexibility of maintaining work/life balance. The experience of the unavoidable online transition during the COVID-19 pandemic might further increase the popularity of online education among students, teachers and educational institutions. However, online education has its unique challenges, one of which is ensuring integrity of online assessments.

In this context, it is extremely important to design online assessments very carefully to ensure academic integrity. To achieve this goal, the authors have conducted an extensive literature review on i) different types of assessments that are suitable for online courses, ii) strategies for ensuring academic integrity while administering those assessments, and iii) methods, tools and technologies available for preventing academic misconduct in online assessments.

After thorough research and analysis of the existing literature, the authors have provided a comprehensive set of multi-faceted recommendations that could be adopted for ensuring academic integrity. The recommendations focus on three important and complementary areas that need to be considered together. The recommendations start with more general and widely applicable strategies related to institutional policies, then outlines student performance related strategies, and concludes with more specific assessment related strategies. The authors strongly believe that this work is not only valuable for unprecedented situations like COVID-19 but also very beneficial for regular online courses.

\section{CONFLICT OF INTEREST}

The authors declare no conflict of interest.

\section{AUTHOR CONTRIBUTIONS}

FS initiated the project and all authors worked on research methodology and questions. Literature review was carried out by all authors equally. Recommendations were deduced by all authors equally; all authors had approved the final version.

\section{REFERENCES}

[1] S. Dendir and R. S. Maxwell, "Cheating in online courses: Evidence from online proctoring," Computers in Human Behavior Reports, vol. 2, pp. $1-10,2020$
[2] P. McGee, "Supporting academic honesty in online courses," Journal of Educators Online, vol. 10, no. 1, pp. 1-31, 2013.

[3] L. Kearns, "Student assessment in online learning: Challenges and effective practices," Journal of Online Learning and Teaching, vol. 8, no. 3, p. 198, 2012

[4] "Effects of proctoring vs. cheating inhibitors on exam scores: Analysis of an online research methods course," Conference Papers American Sociological Association, pp. 1-21,2016.

[5] T. Clark, C. Callam, N. Paul, M. Stoltzfus, and D. Turner, "Testing in the time of COVID-19: A sudden transition to unproctored online exams," Journal of Chemical Education, vol. 97, pp. 3413- 3417, 2020.

[6] A. Fask, F. Englander, and Z. Wang, "On the integrity of online testing for introductory statistics courses: A latent variable approach," Practical Assessment, Research, and Evaluation, vol. 20, pp. 1- 11, 2015.

[7] (2020). Information about Exam. [Online]. Available: https://www.sydney.edu.au/study/coronavirus-infection-university-ofsydney-advice/study-information.html\#exams

[8] (2020). Online Supervised Exams. [Online]. Available: https://www.une.edu.au/current-students/my-course/examinations/olxproject

[9] H. Arksey and L. O'Malley, "Scoping studies: Towards a methodological framework," International Journal of Social Research Methodology, vol. 8, no. 1, pp. 19-32, 2005.

[10] J. Sewell, K. Frith, and M. Colvin, "Online assessment strategies: A primer," MERLOT Journal of Online Learning and Teaching, vol. 6, no. 1, pp. 297-305, 2010.

[11] T. Bretag, R. Harper, K. Rundle, P. M. Newton, C. Ellis et al., "Contract cheating in Australian higher education: A comparison of non-university higher education providers and universities," Assessment and Evaluation in Higher Education, vol. 45, no. 1, pp. 125-139, 2019

[12] C. Ellis, K. Van Haeringen, R. Harper, T. Bretag, I. Zucker et al. "Does authentic assessment assure academic integrity? Evidence from contract cheating data," Higher Education Research and Development, vol. 39, no. 3, 454-469, 2019.

[13] P. Sotiriadou, D. Logan, A. Daly, and R. Guest, "The role of authentic assessment to preserve academic integrity and promote skill development and employability," Studies in Higher Education, vol. 45 , no. 11, pp. 2132-2148, 2019.

[14] ProctorU. (2020). Exam Security done right. [Online]. Available: https://www.proctoru.com/

[15] Proctorio. (2020). Exam integrity by design. [Online]. Available: https://go.proctorio.com/

[16] L. W. Anderson, D. R. Krathwohl, and B. S. Bloom, A Taxonomy for Learning, Teaching, and Assessing: A Revision of Bloom's Taxonomy of Educational Objectives, New York: Longman, Longman, 2001.

[17] B. Teclehaimanot, J. You, D. Franz, M. Xiao, and S. Hochberg, "Ensuring academic integrity in online courses: A case analysis in three testing environments," Quarterly Review of Distance Education, vol. 19, no. 1, pp. 47-52, 2018.

[18] V. Terminiand F. Hayes, "Student identity verification tools and live proctoring in accordance with regulations to combat academic dishonesty in distance education," Online Learning Consortium.

[19] St Petersburg College Libraries. (2019). Plagiarism and academic integrity: Types of academic dishonesty. [Online]. Available: https://spcollege.libguides.com/c.php?g=254383\&p=1695452

[20] J. C. G. Sande, "Calculated questions and e-cheating: A case study," Education Applications \& Developments Advances in Education and Educational Trends Series, vol. 2, no. 3, pp. 91-99, 2015.

[21] R. McHaney, T. Cronan, and D. Douglas, "Academic integrity: Information systems education perspective," Journal of Information Systems Education, vol. 27, no. 3, 2016. 
[22] L. Benson et al., "Developing a university-wide academic integrity E-learning tutorial: a Canadian case," International Journal for Educational Integrity, vol. 15, no. 5, 2019.

[23] D. El-Nakla, B. McNally, and S. El-Nakla, "The importance of institutional support in maintaining academic rigor in e-learning assessment," International Conference on New Trends in Computing Sciences (ICTCS), 2019.

[24] J. Mott, "The detection and minimization of cheating during concurrent online assessments using statistical methods," Collegiate Aviation Review, vol. 28, no. 2, pp. 32-46, 2010.

[25] D. Bedford, J. Gregg, and M. Clinton, "Preventing online cheating with technology: A pilot study of remote proctor and an update of its use," Journal of Higher Education Theory and Practice, vol. 11, no. 2, pp. 41-58, 2011.

[26] M. Smith, M. Dupre, and M. Mackey, "Deterring research paper plagiarism with technology: Establishing a department-level electronic research paper database with e-mail," Journal of Criminal Justice Education, vol. 16, no. 1, pp. 193-204, 2005.

[27] S. Stack, "Effect of the relaxation of a cheating inhibitor on online exam scores: Lengthening time for exam access in a criminology course," Journal of Online Higher Education, vol. 2, no. 1,2018.

[28] M. R. Santos, V. Richman, and J. Jiang, "Online Teaching: A study for the effectiveness of randomized exams," Journal of Instructional Pedagogies, vol. 22, 2019.

[29] J. Golden and M. Kohlbeck, "Addressing cheating when using test bank questions in online classes," Journal of Accounting Education, vol. 52, 2020.

[30] C. Lee. (2020). How to uphold academic integrity in remote learning. [Online].

Available: https://www.turnitin.com/blog/how-to-uphold-academic-integrity-in-r emote-learning

[31] C. Lei and C. K. K. Chan, "Developing meta-discourse through reflective assessment in knowledge building environments," Computers \& Education, vol. 126, pp. 153-169, 2018.

[32] M. Albert and M. Jonathon, "An online testing design choice typology towards cheating threat minimisation," Journal of University Teaching \& Learning Practice, vol. 16, no. 3, 2019.

[33] J. Cramp, J. Medlin, P. Lake, and C. Sharp, "Lessons learned from implementing remotely invigilated online exams" Journal of University Teaching \& Learning Practice, vol. 16, no. 1, 2019.

[34] G. Haus, Y. B. Pasquinelli, D. Scaccia, and N. Scarabottolo, "Online written exams during Covid- 19 crises," in Proc. the International Conference on e-Learning, pp. 79-86, 2020.

[35] Y. Atoum, L. Chen, A. X. Liu, S. D. H. Hsu, and X. Liu, "Automated online exam proctoring," IEEE Transactions on Multimedia, vol. 19, vol. 7, pp. 1609-1624, 2017.

[36] L. Slusky, "Cybersecurity of online proctoring systems," Journal of International Technology and Information Management, vol. 29, no. 1, pp. 56-83, 2020.

[37] B. T. Adetoba, O. Awodele, and S. O. Kuyoro, "A multimedia data mining framework for monitoring e-examination environment," The International Journal of Multimedia \& Its Applications, vol. 9, no. 3, 2017.

[38] H. S. G. Asep and Y. Bandung, "A design of continuous user verification for online exam proctoring on m-learning," in Proc. International Conference on Electrical Engineering and Informatics (ICEEI), pp. 284-289, 2019.

[39] K. Khalaf, M. El-Kishawi, M. Moufti, and S. Al Kawas, "Introducing a comprehensive high-stake online exam to final-year dental students during the COVID-19 pandemic and evaluation of its effectiveness," Medical Education Online, vol. 25, no. 1, pp. 1-10, 2020.

[40] A. Natawiguna and M. M. I. Liem, "Virtualization methods for securing online exam," in Proc. International Conference on Data and Software Engineering (ICoDSE), pp. 1-7, 2016.

[41] M. P. M. Wong and F. M. K. Tang. (2020). Challenges of academic integrity during COVID-19 pandemic. [Online]. Available: https://www.cuhk.edu.hk/eLearning/expo201920/submissions/83-Pap er.pdf

[42] K. D. Mugambi, J. Sansa-Otim, and T. Bulega, "Student and e-assessment authentication in distance learning," in Proc. the Fifth RUFORUM Biennial Regional Conference, vol. 14, no. 3, pp. 65-70, 2016.

[43] A. Lee-Post and H. Hapke, "Online learning integrity approaches: Current practices and future solutions," Online Learning, vol. 21, no. 1, pp. 135-145, 2017.

[44] A. Ullah, H. Xiao, M. Lilley, and T. Barker, "Using challenging questions for student authentication in online examination,"
International Journal for Infonomics, vol. 5, no. 3/4, pp. 631-639, 2012.

[45] C. Y. Chuang, S. D. Craig, and J. Femiani, "Detecting probable cheating during online assessments based on time delay and head pose," Higher Education Research \& Development, vol. 36, no. 6, pp. 1123-1137, 2017.

[46] S. Aisyah, Y. Bandung, and L. B. Subekti, "Development of continuous authentication system on android-based online exam application," in Prof. International Conference on Information Technology Systems and Innovation (ICITSI), pp. 171-176, 2018.

[47] J. R. Young, S. D. Randall, J. L. Jenkins, and I. Pfleger, "Keystroke dynamics: Establishing keyprints to verify users in online courses,' Computers in the Schools, vol. 36, no. 1, 2019.

[48] K. Trezise, T. Ryan, P. Barba, and G. Kennedy, "Detecting contract cheating using learning analytics," Journal of Learning Analytics, vol 6, no. 3, pp. 94-104, 2019.

[49] C. Edwards, D. Whitelock, F. Brouns, M. E. Rodríguez, A. Okada et al., "An embedded approach to plagiarism detection using the TeSLA e-authentication system," in Proc. the Technology Enhanced Assessment Conference (TEA 2018), pp. 1-16, 2019.

[50] Turnitin (2021). Education with Integrity. [Online]. Available: https://www.turnitin.com/

[51] Viper. (2020). Viper Plagiarism Checker. [Online]. Available: https://www.scanmyessay.com/, Accessed: 20 December 2020.

[52] Blackboard SafeAssign. (2021). [Online]. Available: https://www.blackboard.com/teaching-learning/learning-management/ safe-assign

[53] Plagscan. (2021). [Online]. Available: https://www.plagscan.com/en/

Copyright $\odot 2022$ by the authors. This is an open access article distributed under the Creative Commons Attribution License which permits unrestricted use, distribution, and reproduction in any medium, provided the original work is properly cited (CC BY 4.0).

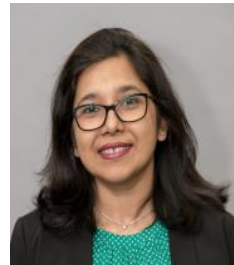

Fariza Sabrina received her Ph.D. in computer science and engineering from the University of New South Wales, Australia in 2005 and Master of Engineering (by research) in electrical and information engineering from the University of Sydney, Australia in 2000. She has many years of research, teaching and industrial experience in information and communication technologies. Her experience includes working as a postdoctoral research fellow and a research scientist in the Networking Research Lab at Commonwealth Scientific and Research Organisation (CSIRO), Australia. Currently she is working as a senior lecturer and discipline lead - Network and Information security in the School of Engineering and Technology at Central Queensland University, Australia. Her current research interest includes networking and information security, internet of things (IoT), cybersecurity, blockchain, and artificial intelligence. She serves as technical program committee member of various conferences. She is a member of IEEE, ACM and ACS

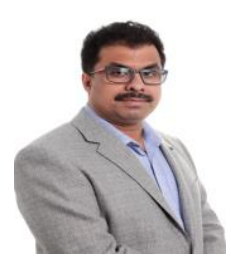

Salahuddin Azad received his $\mathrm{PhD}$ degree in information technology from Monash University, Victoria, Australia in 2007. He obtained his Bachelor of Science degree in computer science and engineering from Bangladesh University of Engineering \& Technology (BUET), Dhaka, Bangladesh in 1999. He is currently working as a lecturer and discipline lead Mobile Applications in School of Engineering and Technology at Central Queensland University. He previously worked as a postdoctoral research fellow at Queensland University Technology (QUT). His research interests include machine learning, image processing, big data and blockchain based system development. He is a member of IEEE and ACS.

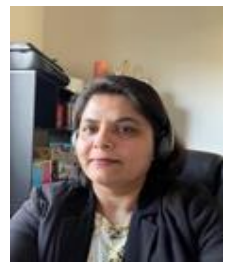

Shaleeza Sohail received her Ph.D. and master in computer science and engineering from the University of New South Wales, Australia in 2006 and 2000 respectively. Currently she is the program convenor (Sydney) for master of IT and Graduate Certificate of IT in the discipline of Computing and IT at The University of Newcastle. She has been teaching undergraduate and postgraduate courses in the field of IT for more than fifteen years and has extensive experience in teaching and learning design and curriculum development. Dr. Sohail has been actively involved in research in various fields of computing and published a number of papers. Her current research interest includes networking, quality of 
service, internet of things (IoT), cybersecurity, blockchain, and machine learning. She is a member of ACS.

Sweta Thakur received her $\mathrm{PhD}$ degree in 2010 in computer science and engineering with specialization in digital image processing and pattern recognition. She has received Master and Bachelor degree in computer science and engineering. She worked as a senior lecturer and an Assistant Professor in CSE and IT over last two decades. She is currently the Head of Program for the BIT (bachelor of IT) at King's Own Institute
(KOI). Her research areas of interest are medical imaging, face recognition, machine learning, IoT and blockchain. She is a member of IEEE and ACS. 